\title{
Impacts of peat on nitrogen conservation and fungal community composition dynamics during food waste composting
}

\author{
Zaihua He ${ }^{1}$, Qiang Li ${ }^{1}$, Xiaoyi Zeng ${ }^{1}$, Kai Tian ${ }^{2}$, Xiangshi Kong ${ }^{1}$ and Xingjun Tian ${ }^{1,3^{*}}$
}

\begin{abstract}
Peat, as a heterogeneous mixture of decaying plant debris and microbial residues, has been widely used in many fields. However, little research focused on the impact of peat addition on food waste composting. To fill this gap, a composting experiment of food waste mixed with five varying percent peat $0,5,10,15$, and $20 \%$ (w/W, dry weight) was designed to investigate the effect of different dosages of peat on nitrogen conservation, physiochemical parameters, and fungal community dynamics during composting. The results showed that adding peat elevated the peak temperature of composting, lowered final $\mathrm{pH}$, reduced ammonia emissions and increased the final total nitrogen content. Compared to control, adding 5, 10,15, and 20\% peat decreased ammonia emissions by 1.91, 10.79, 23.73, and $18.26 \%$, respectively, during 42 days of composting. Moreover, peat addition increased fungal community diversity especially during maturation phase. The most two abundant phyla were Basidiomycota and Ascomycota in all treatments throughout the composting process. At the end of composting, in treatments with adding 10 and $15 \%$ peat, the richest fungi were Scedosporium spp. and Coprinopsis spp., respectively. Simultaneously, canonical correlation analyses showed that $\mathrm{pH}$, moisture content, and seed germination index had significant association with fungal community composition. The study also showed that fungal community and nitrogen conservation had no direct obvious relation during composting. Overall, the results suggest that the addition of peat could efficiently enhance nitrogen conservation through reduction of ammonia emissions and 15\% peat addition is the optimal formula for food waste composting.
\end{abstract}

Keywords: Food waste, Composting, Peat, Nitrogen conservation, Fungal community

\section{Introduction}

As a consequence of rapid development in the foodservice industry and the continued rise in standards of living, vast amounts of food waste have been generated. For example, in China, food waste comprises about $56 \%$ of municipal solid waste, making it the majority contributor [1]. Traditional disposal of food waste is either in landfills or via incineration; however, these disposal options have many drawbacks such as secondary pollution from leaching, gas leakage, dioxins, and heavy metals [2]. The

\footnotetext{
*Correspondence: tianxj@nju.edu.cn

${ }^{1}$ School of Life Sciences, Nanjing University, Nanjing 210023, Jiangsu,

China

Full list of author information is available at the end of the article
}

physical and chemical characteristics of food waste (e.g., high moisture content, high organic to ash ratio, easily decayed) make it a potential high-quality candidate for biological treatment [2]. Therefore, a reasonable, efficient, and eco-friendly disposal method for food waste is becoming a major worldwide concern.

Composting, an environmentally-friendly technology, is considered to be an effective organic waste management strategy for food waste where a biochemical process converts organic matter $(\mathrm{OM})$ into relatively stable humus-like substances which can then be used as a soil additive or organic fertilizer [3, 4]. Moreover, composting is an ideal method for food waste treatment because of its simple process and easy operation [5]. However, food waste composting also has some disadvantages. One of 
them is the loss of nitrogen, mainly in the form of ammonia $\left(\mathrm{NH}_{3}\right)$. Komilis and Ham [6] reported that about 65\% of the initial nitrogen can be volatized as $\mathrm{NH}_{3}$ during food waste composting. $\mathrm{NH}_{3}$ emissions not only reduce the fertilization value of compost, but also cause environment problems such as odor, acidification, and eutrophication of ecosystems [7]. Nonetheless, many studies have shown that the reduction of $\mathrm{NH}_{3}$ loss is possible during composting, particularly with additives [8-11]. For example, Wang et al. [8] reported that $\mathrm{NH}_{3}$ emissions was reduced by $23.3-40 . \%$ via struvite formation, Al-Jabi et al. [9] reported that zeolite could reduce nitrogen losses by $40 \%$ of the initial total nitrogen (TN) and Chan et al. [10] reported that zeolite could reduce $\mathrm{NH}_{3}$ emissions by $18 \%$ during food waste composting.

Peat is a heterogeneous mixture of decomposed plant materials, microbial remains, and their secondary metabolites that have accumulated in a water-saturated environment due to be inhibited decay under acidic and anaerobic conditions [12]. Peat has a very high affinity for $\mathrm{NH}_{3}$ and can absorb $2.5 \%$ of its dry weight in $\mathrm{NH}_{3}$ [13, 14]. For example, Witter and Kirchmann [14] reported that peat, as an adsorbent, reduced overall $\mathrm{NH}_{3}$ losses by $59 \%$ when placed in the spent air-stream during the first 8 days of manure decomposition. Additionally, peat has a high air space volume and can retain large amounts of water, which could provide a suitable habitat for microorganisms during composting [12]. Finally, peat is convenient to use and has been widely used in horticulture and agriculture $[15,16]$. But peat is a finite resource, and as demand has increased in recent years, price has also risen. Farrell and Jones [17] reported that food could partially replace peat and up to $75 \%$ substitution of peat by catering waste-derived composts would be unaffected for the sunflower growth. For these reasons, adding peat into food waste composting for nitrogen conservation should be very effective as well as might produce high-quality compost which have potential to replace peat. However, to our knowledge, there is no study that assessed the impact of peat additions on food waste composting process.

Microbial population, mainly bacteria and fungi, is of great importance for the successful biodegradation of organic waste during composting. Numerous studies have investigated bacteria community dynamics due to their large surface area, fast population growth rate, strong metabolism function, and resistance to high temperature that those experienced during the composting process [18-20]. The relationship between bacterial communities and environmental factors has been studied during composting process. For example, Wang et al. [19] reported that bacterial community were influenced by oxidation reduction potential (ORP), moisture and temperature in cow manure composing and Wang et al. [21] reported that the most critical driving factor for bacterial succession was $\mathrm{pH}$ in food waste composting. Meantime, fungi also play a significant role in OM decomposition and carbon cycling, especially cellulolytic and lignolytic degradation [22, 23]. However, fungal community succession dynamics and the relationship between fungal community structure and physicochemical parameters during food waste composting remains unclear.

Therefore, in this study, we aimed to: (1) investigate the potential effects of peat addition on nitrogen conservation and maturity of compost; (2) reveal fungal community composition dynamics during the composting process; and (3) assess associations between fungal community and physicochemical parameters in food waste composting.

\section{Materials and methods Composting materials}

A synthetic food waste for the experiment was prepared by mixing potatoes, carrots, ground pork, steamed rice and cooked soybean as in $\mathrm{Yu}$ and Huang [24]. Sawdust was used to regulate the $\mathrm{C} / \mathrm{N}$ ratio to 25 , and the initial moisture content of compost substrate was adjusted to $\sim 65 \%$ using deionized water. All raw materials above were purchased from a local grocery store. Food items were chopped into pieces of approximately $5 \mathrm{~mm}$ in diameter using a food processor to obtain uniform particle size and then mixed well before proceeding into the compost reactions. The peat used in this study was Canada Growing mix (https://m.tb.cn/h.VXPMPlz). A control (P0-without peat) and four peat addition treatments (P5, P10, P15, P20-with 5, 10, 15, 20\% peat addition, respectively) were used to evaluate the effects of peat on food waste composting. Each treatment had three replicates. The detailed composition of composting raw materials is shown in Table 1 . Peat addition

Table 1 Composition of raw composting materials (kg, fresh weight)

\begin{tabular}{llllll}
\hline Component & \multicolumn{4}{l}{ Treatment } \\
\cline { 2 - 6 } & P0 & P5 & P10 & P15 & P20 \\
\hline Potato & 1.27 & 1.27 & 1.27 & 1.27 & 1.27 \\
Carrot & 1.96 & 1.96 & 1.96 & 1.96 & 1.96 \\
Ground pork & 0.35 & 0.35 & 0.35 & 0.35 & 0.35 \\
Steamed rice & 2.01 & 2.01 & 2.01 & 2.01 & 2.01 \\
Cooked soybean & 1.96 & 1.96 & 1.96 & 1.96 & 1.96 \\
Sawdust & 1.50 & 1.50 & 1.50 & 1.50 & 1.50 \\
Peat & 0.00 & 0.25 & 0.50 & 0.75 & 1.00 \\
\hline
\end{tabular}


percentages was determined by initial dry mass of food waste. Selected physical and chemical properties of the synthetic food waste, sawdust, and peat were measured (Table 2).

\section{In-vessel composting system and analytical methods}

The in-vessel composting system used was a cylindrical composting reactor. The schematic diagram of the

Table 2 Properties of the synthetic food waste, sawdust, and peat used in the study: values are the mean of triplicates (dry weight), values in parentheses are standard deviation $(n=3)$

\begin{tabular}{|c|c|c|c|}
\hline Parameters & Food waste & Sawdust & peat \\
\hline TC (\%) & $48.64(0.06)$ & $44.75(0.52)$ & $45.51(0.55)$ \\
\hline TN (\%) & $3.30(0.10)$ & $0.20(0.01)$ & $0.80(0.03)$ \\
\hline $\mathrm{C} / \mathrm{N}$ & $14.73(0.42)$ & $227.61(4.67)$ & $56.94(1.97)$ \\
\hline $\mathrm{EC}(\mathrm{mS} / \mathrm{cm})$ & $1.18(0.02)$ & $0.44(0.00)$ & $0.64(0.02)$ \\
\hline $\mathrm{pH}$ & $4.67(0.07)$ & $7.16(0.09)$ & $6.08(0.07)$ \\
\hline $\mathrm{NH}_{4}^{+}(\mathrm{mg} / \mathrm{g})$ & $2.01(0.12)$ & $0.00(0.00)$ & $0.95(0.08)$ \\
\hline Ash (\%) & $2.83(0.12)$ & $4.71(1.27)$ & $7.59(0.22)$ \\
\hline Moisture content (\%) & $73.72(0.36)$ & $7.41(1.07)$ & $60.81(0.40)$ \\
\hline
\end{tabular}

$\mathrm{TC}$, total carbon; $\mathrm{TN}$, total nitrogen; $\mathrm{C} / \mathrm{N}$, carbon/nitrogen ratio; $\mathrm{EC}$, electrical conductivity; $\mathrm{NH}_{4}^{+}$, ammonium in-vessel composting system is illustrated in Fig. 1. The reactor was made of a high density polyethylene column (5 mm thickness) with a working volume of $30 \mathrm{~L}(280 \mathrm{~mm}$ diameter and $500 \mathrm{~mm}$ height). To prevent conductive and reflective heat loss, a layer of $30 \mathrm{~mm}$ rubber aluminum foil heat-insulating material was wrapped around the reactor. Small holes were drilled at the bottom of the containers to allow for water leaching. Aeration was provided from the reactor bottom at a flow rate of $100 \mathrm{~L} / \mathrm{h}$ during the entire composting process via aerator pump. The experiment was operated for 42 days.

Temperature variation was monitored and recorded every 15 min via thermometer (SIN-RC-4, China) placed in the center of the reactor throughout the composting process. Ambient temperature was monitored and logged every 15 min. To evaluate $\mathrm{NH}_{3}$ emissions, $\mathrm{NH}_{3}$ was trapped in boric acid (2\%) and then titrated against $\mathrm{H}_{2} \mathrm{SO}_{4}(0.01 \mathrm{~mol} / \mathrm{L})$. The composting materials in each reactor was removed, weighted and thoroughly mixed manually in a large vessel on days $0,3,7,14,21,28,35$, and 42 before sampling. Subsequently, $150 \mathrm{~g}$ of wellmixed compost from each reactor was collected and divided into two parts. One half of the sample was stored at $4{ }^{\circ} \mathrm{C}$ for physicochemical parameter analyses and the other at $-20^{\circ} \mathrm{C}$ for DNA extraction.

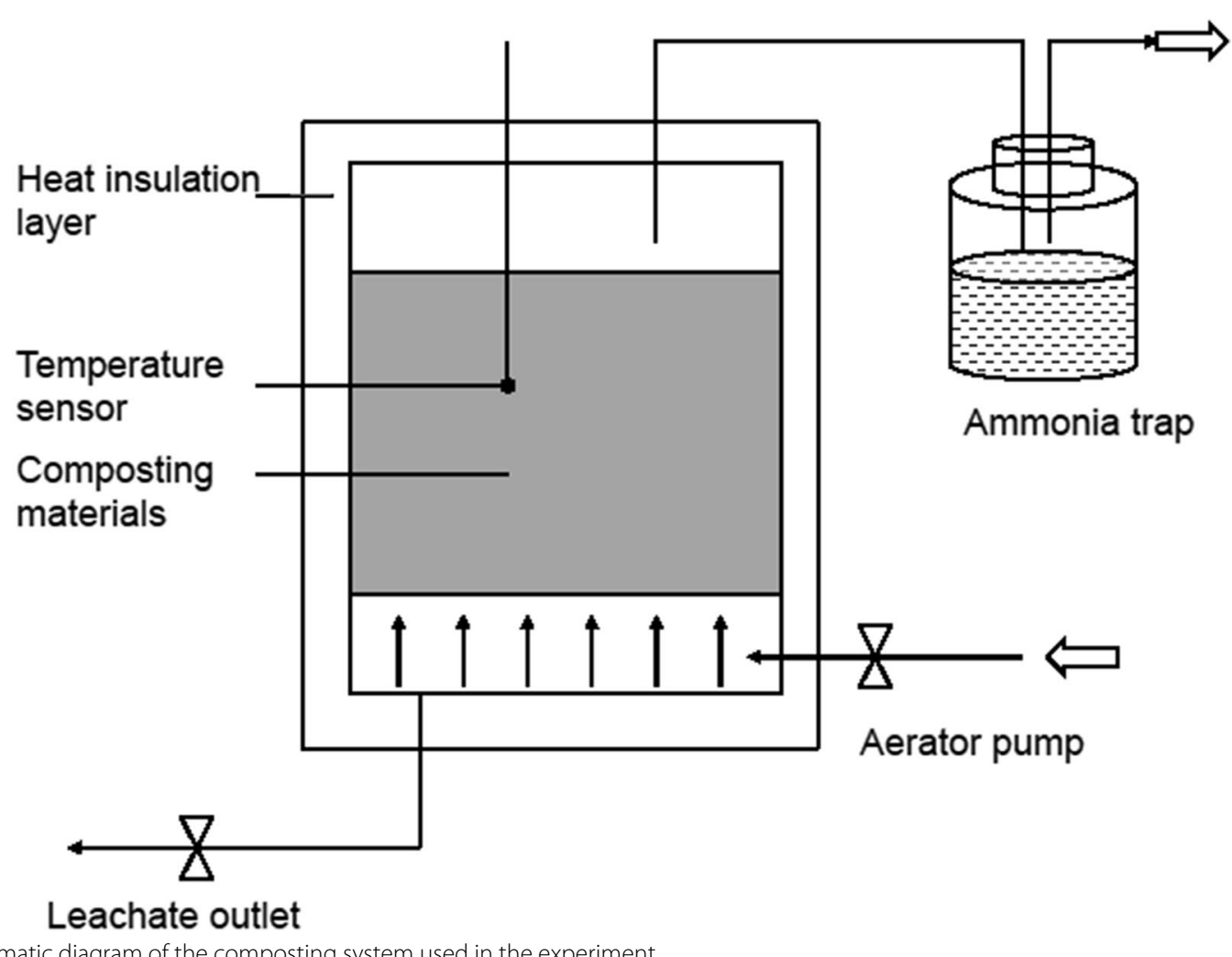

Fig. 1 Schematic diagram of the composting system used in the experiment 
Moisture content (MC) was determined via drying at $105{ }^{\circ} \mathrm{C}$ until samples reached a constant mass. Dried samples were ignited at $550{ }^{\circ} \mathrm{C}$ in a muffle furnace for $6 \mathrm{~h}$ to determine $\mathrm{OM}$ content. The $\mathrm{pH}$, electrical conductivity (EC), and seed germination index (GI) were analyzed by using a 1:10 (w/v) aqueous extract of the fresh compost samples with deionized water. The $\mathrm{pH}$ and $\mathrm{EC}$ were measured using a $\mathrm{pH}$-meter and a conductimeter, respectively. The germination test was measured using cabbage seeds according to Yang et al. [25] and calculated using the following formula (1):
All of this was finished by Shanghai Genergy Biotechnology Co., Ltd, Shanghai, China.

\section{Statistical analysis}

Means and standard deviations of triplicate measurements were calculated, and data were analyzed with oneway ANOVAs with $p<0.05$ considered significant. The least significance difference test at $5 \%$ probability was used to determine the significance of the difference in the mean values. The physicochemical data were analyzed

$$
G I(\%)=\frac{[\text { Seed germination of treatment } \times \text { Root length of treatment }]}{[\text { Seed germination of control } \times \text { Root length of control }]} \times 100
$$

Ammonium $\left(\mathrm{NH}_{4}^{+}\right)$was extracted with $2 \mathrm{~mol} / \mathrm{L} \mathrm{KCl}$ $(1: 20, \mathrm{w} / \mathrm{v})$, then $\mathrm{NH}_{4}^{+}$was determined using the indophenol blue method followed by colorimetry [26]. Total carbon (TC) and TN were determined using an elemental analyzer (CHN-O-Rapid, Germany). Loss of nitrogen was calculated according to the formula as below (2) [27]:

$$
N \text { loss }(\%)=100-100 \frac{X_{0} N_{t}}{X_{t} N_{0}}
$$

where $X_{0}$ and $X t$ are the ash content at time $=0$ and time $=t, N_{0}$ and $N t$ are the nitrogen content at time $=0$ and time $=t$.

DNA extraction, metagenomics sequencing and analysis DNA extraction from fresh compost samples for metagenomic sequencing was conducted with the QIAamp Fast DNA Stool Mini Kit (Qiagen, Germany), following the manufacturer's instructions. The fungal community of the samples was characterized by amplicon sequencing of the fungal internal transcribed spacer using fungal primers ITS1F (5'-GATTGAATGGCTTAG TGAGG-3') and ITS2R (5'-CTGCGTTCTTCATCGAT$3^{\prime}$ ). Compost samples were sequenced using the Illumina HiSeq 2000 platform (Illumina, Inc., USA) at Shanghai Genergy Biotechnology Co., Ltd. DNA libraries were prepared following manufacturer's instructions. Cluster generation, template hybridization, isothermal amplification, linearization, blocking, and denaturing and hybridization of the sequencing primers were performed according to the workflow indicated by the provider. Flexbar was used to trim adapters [28], and a rarefied operational taxonomic unit (OTU) table was generated using QIIME [29]. Consensus sequences were constructed for each taxonomic cluster, and OTUs were constructed by clustering these consensus sequences at $97 \%$ identity. ITS gene sequences were assigned using the UNITE Database [30]. using IBM SPSS Statistics 19.0 for Windows (SPSS Inc., Chicago, IL, USA), and the fungal community analysis were performed in R version 3.6.0 (R Foundation for Statistical Computing, Vienna, Austria).

\section{Results and discussion}

\section{Changes in temperature, $\mathrm{pH}$ and electrical conductivity}

Temperature, one of the most important factors of composting, influences the succession and evolution of microbiological communities throughout food waste composting [31, 32]. Temperature profiles (Fig. 2a) in all treatments showed a similar dynamic pattern with time which was in line with those of most aerobic composting studies and underwent three typical phases: mesophilic, thermophilic, and cooling [33]. After composting started, temperature increased sharply and all treatments reached the thermophilic phase $\left(>50^{\circ} \mathrm{C}\right)$ on the second day of incubation and lasted for 8 days, except for P20, which reached the thermophilic phase on day 1 and remained for 10 days. Among them, the control reached the peak temperature of $68.1^{\circ} \mathrm{C}$ on day 2 of composting. However, treatments P5, P10, P15, and P20 reached peak temperature (69.7, 70.4, 72.2 , and $73.2^{\circ} \mathrm{C}$, respectively) on day 4 . The rapid rose of temperature at the beginning of composting was attributed to the rapid biodegradation of easily available OM and the duration of thermophilic phase of all treatments was enough to obtain a sanitation product. Adding peat elevated the peak temperature of composting, possibly due to the increasing air space and improving aerobic conditions of composting mixture by peat, which enhanced the capability of microbes to degrade OM during composting, especially for treatment P20, in which higher peat might provide the optimum condition as well as more nutrient substances (e.g., nitrogen) for microorganisms to the growth and reproduction during the early phase of composting. These biological processes lead to the release of metabolic heat hence heightened temperature in these 

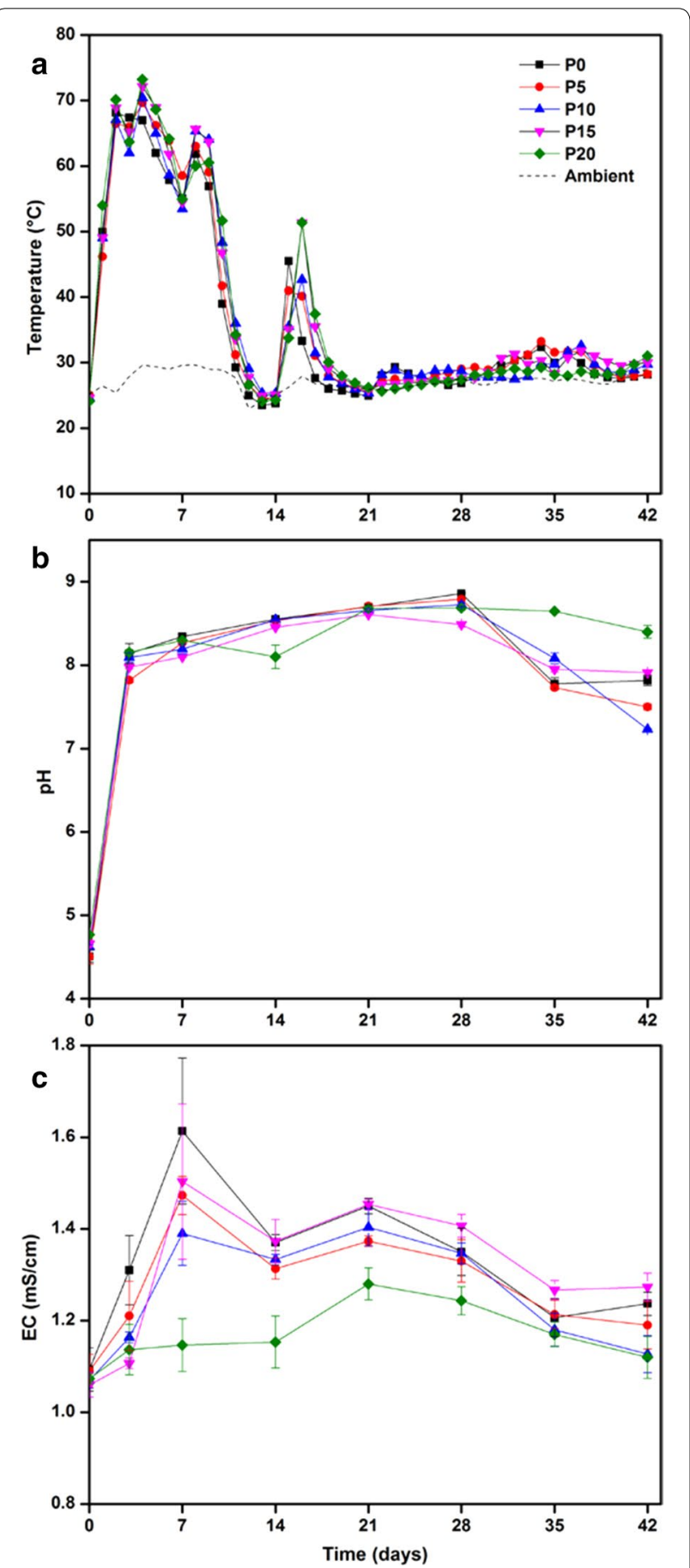

Fig. 2 Changes in temperature (a), $\mathrm{pH}$ (b) and EC (c) during food waste composting time. P0 — Control, P5 - 5\% Peat, P10 - 10\% Peat, P15-15\% Peat, P20 - 20\% Peat. Values are mean and standard deviations ( $\pm S D, n=3$ )

treatments [31, 34]. After 21 days of composting, the temperature of all treatments dropped to ambient temperature, indicating the exhaustion of easily degradable OM and the composting entered the curing phase.
The $\mathrm{pH}$ changes of all treatments throughout the composting process were apparent (Fig. 2b). The initial $\mathrm{pH}$ values in all treatments were acidic which might be attributed to organic acids produced by microorganisms before composting $[35,36]$. The addition of peat had no significant effect on the initial $\mathrm{pH}(p>0.05)$. Moreover, $\mathrm{pH}$ changes had similar trends over all treatments. In the first 3 days of composting, $\mathrm{pH}$ values of all treatments increased rapidly, likely due to the volatilization and consumption of organic acids under high temperature and the production and accumulation of $\mathrm{NH}_{4}^{+}[32,35,37$. Then, $\mathrm{pH}$ values remained constant until the day 28 of composting. After then, $\mathrm{pH}$ decreased across all treatments, which might be attributed to the microbial nitrification processes that resulted in the reduction of $\mathrm{NH}_{4}^{+}$ and the production of $\mathrm{NO}_{3}^{-}$as well as the release of $\mathrm{H}^{+}$ [38]. However, final $\mathrm{pH}$ values were significantly different among treatments $(p<0.01)$. Similar $\mathrm{pH}$ trends were observed where different supplemental carbon sources were added to sewage sludge composting [39].

Electrical conductivity (EC) also showed similar trends across all treatments, except P20 (Fig. 2c). We observed rapid increases in EC during the initial stage due to the production and accumulation of soluble components (e.g., $\mathrm{NH}_{4}^{+}$) from OM degradation $[8,40]$. After the first week, EC gradually decreased until the end of composting except for a small increase on day 21. Decreases in EC were mainly caused by the degradation and reduction of soluble components, e.g., the volatilization of organic carbon and the humification of composting materials transformed salt and micro-molecular organic acids to macro-molecular humus [41]. Final EC values were $1.24,1.19,1.13,1.27$, and $1.12 \mathrm{mS} / \mathrm{cm}$ in treatments P0, $\mathrm{P} 5, \mathrm{P} 10, \mathrm{P} 15$, and $\mathrm{P} 20$, respectively, which were all below $4 \mathrm{mS} / \mathrm{cm}$ and have no harm to plants [11]. Adding peat had no significant effects on EC values throughout the food waste composting process $(p>0.05)$.

\section{Nitrogen dynamics during composting}

Ammonia $\left(\mathrm{NH}_{3}\right)$ is an inevitable byproduct of composting and is undesirable because it results in environmental pollution and a decreases compost quality [7, 10]. As shown in Fig. 3a, only a small amount of $\mathrm{NH}_{3}$ was detected in all treatments during the first 3 days of composting, which were the results of relatively low $\mathrm{NH}_{4}^{+}$ concentration and high MC. Then, $\mathrm{NH}_{3}$ emissions in all treatments sharply increased under high temperature and high $\mathrm{pH}$ conditions in the following week, exacerbated by rapid aerobic degradation (ammonification) of organic nitrogen compounds [10, 42]. Only a small amount of $\mathrm{NH}_{3}$ was released when temperature dropped to ambient and easily degradable $\mathrm{OM}$ has been exhausted. $\mathrm{NH}_{3}$ 

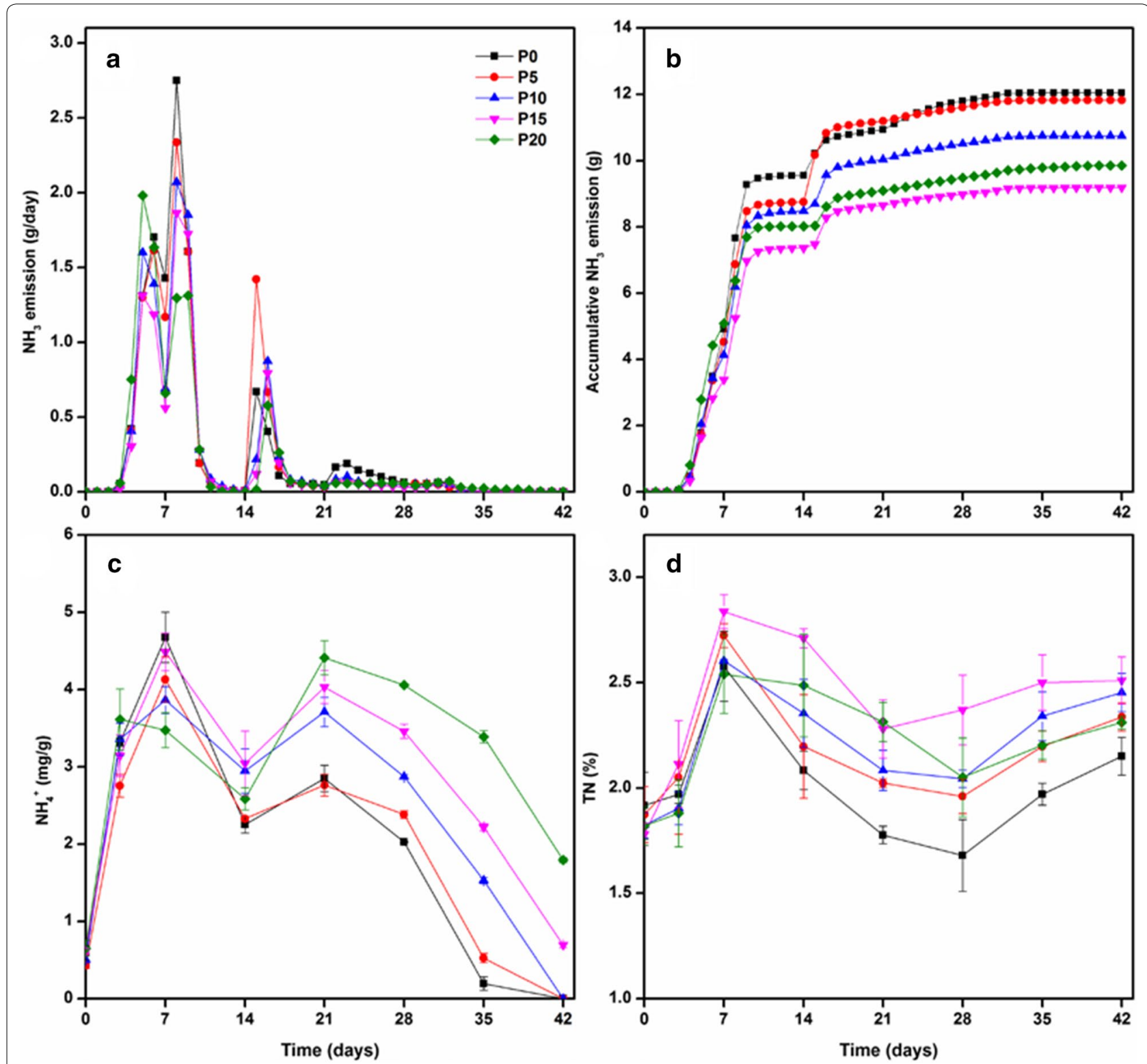

Fig. 3 Changes in ammonia emissions (a), cumulative ammonia emissions (b), ammonium (c), and total nitrogen (d) during food waste composting time. P0—Control, P5—5\% Peat, P10-10\% Peat, P15-15\% Peat, P20—20\% Peat. Values are mean and standard deviations ( \pm SD, $n=3)$

emissions dynamic with time were significantly paralleled with temperature dynamic with time $(p<0.01)$.

Most $\mathrm{NH}_{3}$ was emitted during the first 10 days (Fig. 3b), accounting for more than $70 \%$ total $\mathrm{NH}_{3}$ emissions amount. This high proportion was probably due to quantities of easily degradable nitrogenous $\mathrm{OM}$ being degraded by microorganisms in the early stages of composting. Similar results were reported by Awasthi et al. [43] with biosolid composting. Total $\mathrm{NH}_{3}$ emissions were $12.05,11.82,10.75,9.19$, and $9.85 \mathrm{~g}$ in treatments
P0, P5, P10, P15, and P20, respectively. Compared to the control, adding $5-20 \%$ peat reduced $\mathrm{NH}_{3}$ emissions by 1.91-23.73\% during food waste composting. Overall, our results indicate that the addition of peat can reduce $\mathrm{NH}_{3}$ emissions effectively. One possible reason is that peat has an extremely high affinity for $\mathrm{NH}_{3}$ and a good absorption capacity to absorb $\mathrm{NH}_{3}$. Peat, as an absorbent, has been proved that it was effective in reducing $\mathrm{NH}_{3}$ emissions in manure decomposition [14]. Another possible reason is that peat has an outstanding cation exchange 
capacity which is beneficial for absorbing a wide range of cations such as ammonium. Of all treatments, the highest reduced $\mathrm{NH}_{3}$ loss was found in $\mathrm{P} 15$ (23.73\%), suggesting that $15 \%$ peat is the optimal addition to reduce $\mathrm{NH}_{3}$ emissions during food waste composting.

Concentrations of $\mathrm{NH}_{4}^{+}$in all treatments increased quickly after the start of composting (Fig. 3c), which is mainly attributed to the active degradation of $\mathrm{OM}$ accompanied by the ammonification during the thermophilic phase [10]; and then, decreases in $\mathrm{NH}_{4}^{+}$occur because of $\mathrm{NH}_{3}$ emissions under high temperature and high $\mathrm{pH}$ conditions during the subsequent period [37]. However, the content of $\mathrm{NH}_{4}^{+}$increased again on day 21 , potentially caused by the ammonification coincided with OM degradation and the temperature spike between day 14 and 21. After day 21, the concentration of $\mathrm{NH}_{4}^{+}$ decreased until the end of composting. The reduction of $\mathrm{NH}_{4}^{+}$concentration might be due to the volatilization of $\mathrm{NH}_{3}$ and the nitrification processes during composting. Compared to the control, adding $5-20 \%$ peat retained more $\mathrm{NH}_{4}^{+}$concentration during the cooling phase of composting.

TN content of all treatments increased rapidly initially (Fig. 3d). This may have been caused by the rapid degradation of $\mathrm{OM}$ and subsequent net loss of composting mass in the form of $\mathrm{CO}_{2}[10]$. TN content then decreased across all treatments, mainly attributable to net losses of nitrogen in the form of $\mathrm{NH}_{3}$. Finally, TN content increased again until the end of composting. Increases of TN in the final stage were likely due to the net loss of composting mass, the nitrification process, and the assimilation of microorganisms. Final TN contents were $2.15,2.34,2.45,2.51$, and $2.31 \%$ in treatments P0, P5, P10, P15, and P20, respectively. Therefore, compared to the control, treatments with peat increased the final TN content by $7.44-16.74 \%$ after composting. Moreover, the addition of peat had a significant effect on final TN content $(p<0.01)$, and the final TN content in the control was lower than treatments with peat $(p<0.05)$. At the end of composting, the loss of nitrogen was $49.19,38.40,36.26,31.06$, and $36.33 \%$ in treatments P0, P5, P10, P15 and P20, respectively. Adding peat significantly increased the final TN content and reduced the nitrogen loss during food waste composting. On the one hand, peat could reduce $\mathrm{NH}_{3}$ volatilization by adsorbing $\mathrm{NH}_{3} / \mathrm{NH}_{4}^{+}$during composting [14]. On the other hand, the cellular structure of peat has an enhanced water holding capacity, creating a favorable microenvironment for nitrifying bacteria and ammonia-assimilating microorganisms that could convert $\mathrm{NH}_{3} / \mathrm{NH}_{4}^{+}$to nitrate or organic nitrogen and ultimately resulting in nitrogen-rich compost [39].

\section{Change in $\mathrm{C} / \mathrm{N}$ ratios and seed germination indices during composting}

Carbon to nitrogen ratios $(\mathrm{C} / \mathrm{N})$ is one of the most widely used parameters that confirm the rate of composting processes as well as end product maturity [10, 37]. The $\mathrm{C} / \mathrm{N}$ in all treatments dropped sharply when the composting started (Fig. 4a), which was due to the rapid degradation of $\mathrm{OM}$ and the mineralization rate of organic nitrogen lower than that of organic carbon [25]. After the first week, the $\mathrm{C} / \mathrm{N}$ in treatments $\mathrm{P} 0, \mathrm{P} 5$, and $\mathrm{P} 20$ increased and lasted for 21 days, while increase of $\mathrm{C} / \mathrm{N}$ in treatments P10 and P15 only lasted for 14 days. After that, $\mathrm{C} / \mathrm{N}$ in all treatments decreased until the end of composting. Final $\mathrm{C} / \mathrm{N}$ in all treatments was $18.34,17.19$, $16.63,16.43$, and 17.40 , respectively, which were within the standard measurement $(<20)$ that indicates maturity

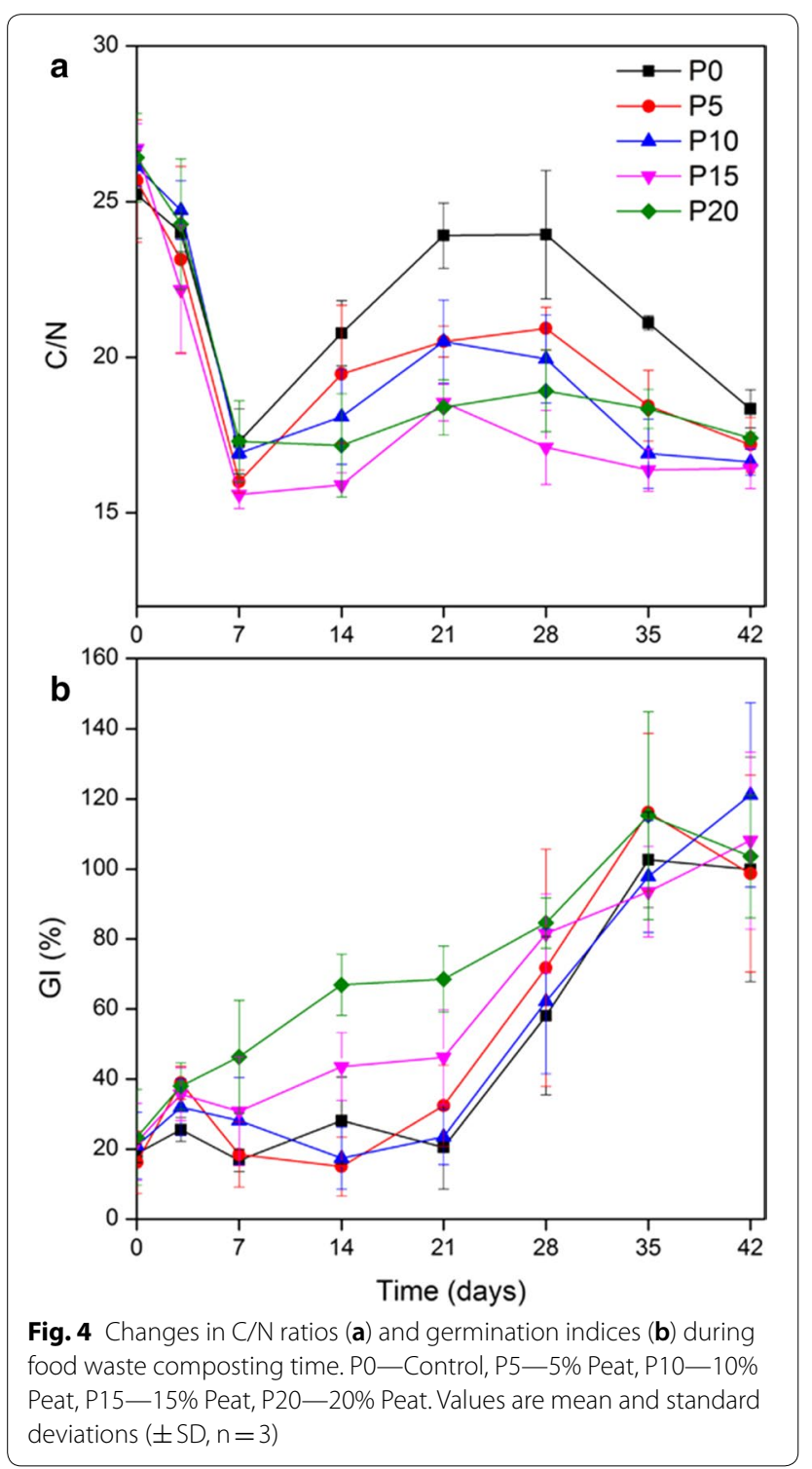


of the compost [44]. Peat had a significant effect on the final $\mathrm{C} / \mathrm{N}$ and the $\mathrm{C} / \mathrm{N}$ in the control was significantly higher than adding $5-15 \%$ peat treatments during composting $(p<0.05)$.

Seed germination indices (GI) is a more direct indicator for compost maturity since it directly tests whether the finished compost is inhibitory to plants or not [44, 45]. The changes of GI in all treatments over time are shown in Fig. 4b. In the early stages of composting, the GI of all treatments was relatively low. This phenomenon was attributable to high concentrations of volatile organic acids and $\mathrm{NH}_{4}^{+}$inhibiting plant growth $[45,46]$. On day 28, the GI of treatments P15 and P20 were $81.53 \%$ and $84.56 \%$, respectively, which exceeded $80 \%$ and was commonly considered non-toxic and mature [46]. The result indicated that adding $15-20 \%$ peat could shorten compost maturity time. The possible reason was that adding $15-20 \%$ peat provided a favorable microenvironment for the growth and reproduction of microorganisms, which accelerated OM degradation and ultimately facilitated compost maturity. Final GI in treatments P0, P5, P10, P15, and P20 were 99.90, 98.67, 121.12, 108.07, and $103.59 \%$, respectively, and all exceeded $80 \%$. Peat had no significant effect on final GI values during composting $(p>0.05)$.

\section{The dynamics of fungal community composition during composting}

A total of 1,185,035 raw pairs of fungal community were obtained from composting samples. After filtering, a total of 1,027,185 reads were obtained and clustered into 188 different fungal OTUs based on $97 \%$ nucleotide similarity. The Shannon index across samples decreased initially and then increased in all treatments except for fluctuations in P20 (Table 3), and the Shannon index ranged from $0.1002,0.0982,0.0687,0.2383$, and 0.2146 to 0.6847 , 0.7716, 1.7790, 0.9264, and 0.7047 in treatments P0, P5, P10, P15, and P20, respectively. That Shannon index reached the maximum at the mature phase was because fungi are the main decomposers of the refractory $\mathrm{OM}$ during composting [47]. Additionally, the result indicated that adding $5-15 \%$ peat increased the variation scope in fungal diversity and adding peat elevated the fungal diversity, especially the mature phase, which might be attributed to the variation of physicochemical parameters during composting. This result was similar to other authors $[48,49]$, who found that fungal diversity variation were influenced by physicochemical variation and the properties of applied additives.

The change of top ten fungal OTUs of relative abundances (RAs) throughout the composting process are shown in Fig. 5 and these ten fungal OTUs were accounted for $91.35-99.96 \%$ of the entire representative of OTUs in

\begin{tabular}{|c|c|c|c|c|c|}
\hline \multirow[t]{2}{*}{ Treatment } & \multicolumn{5}{|c|}{ Time(days) } \\
\hline & 3 & 7 & 14 & 21 & 42 \\
\hline PO & 0.5859 & 0.1002 & 0.1771 & 0.6847 & 0.6740 \\
\hline P5 & 0.7698 & 0.2347 & 0.0982 & 0.7139 & 0.7716 \\
\hline P10 & 1.7790 & 0.0687 & 0.2704 & 0.8821 & 0.9240 \\
\hline P15 & 0.8680 & 0.2383 & 0.3004 & 0.6935 & 0.9264 \\
\hline P20 & 0.2146 & 0.6899 & 0.2867 & 0.4508 & 0.7047 \\
\hline
\end{tabular}

all samples. Basidiomycota, a fungal phylum playing an important role in lignocellulose degradation, was the predominant phylum, and their RA was above $60 \%$ in all samples except for P10 at day 42 when Ascomycota was the dominant phylum accounting for $87.01 \%$ of the assemblage. The second most abundant phylum was Ascomycota. Similar results were reported by Li et al. [50], where pine leaf biochar were added into pig manure compost. Composting feedstock could affect the fungal community and their RAs because the physical and chemical characteristics in the substrate have a significant impact on the environment [51]. In the first 21 days of composting, the richest fungus was the unclassified_Tremellomycetes (52.71-99.15\%) in all samples (Fig. 5), and the second most abundant fungus was Vishniacozyma spp., which belongs to Basidiomycota phyla. At the end of composting, the main fungus was still unclassified_Tremellomycetes (62.59-77.12\%) in treatments P0, P5, and P20. However, in treatments $\mathrm{P} 10$ and P15, the predominant fungi were Scedosporium spp. (72.43\%) and Coprinopsis spp. (64.88\%), respectively. The second most dominant fungus were Scopulariopsis spp. (21.01\%), Scedosporium spp. (35.64\%), unclassified_ Tremellomycetes (35.64\%), unclassified_Tremellomycetes (12.48\%) and Unclassified_Ascomycota (19.78\%), respectively, in treatments P0, P5, P10, P15, and P20. Ma et al. [47] reported that adding matured compost increased the proportion of Scedosporium spp. during sewage sludge composting. Coprinopsis spp. was one of the richest genera in compost [50]. Scedosporium spp. can secrete proteases [52], and Coprinopsis spp. can degrade cellulose [53], both of which could promote OM degradation during composting. The result indicated that adding 5-15\% peat might promote OM degradation by altering fungal community at matured stage of composting.

\section{The effect of peat on the fungal community during composting}

We used nonmetric multidimensional scaling (NMDS) at the total OUT level to test the influence of different amounts of peat on the fungal community structure during food waste composting through time (Fig. 6). 


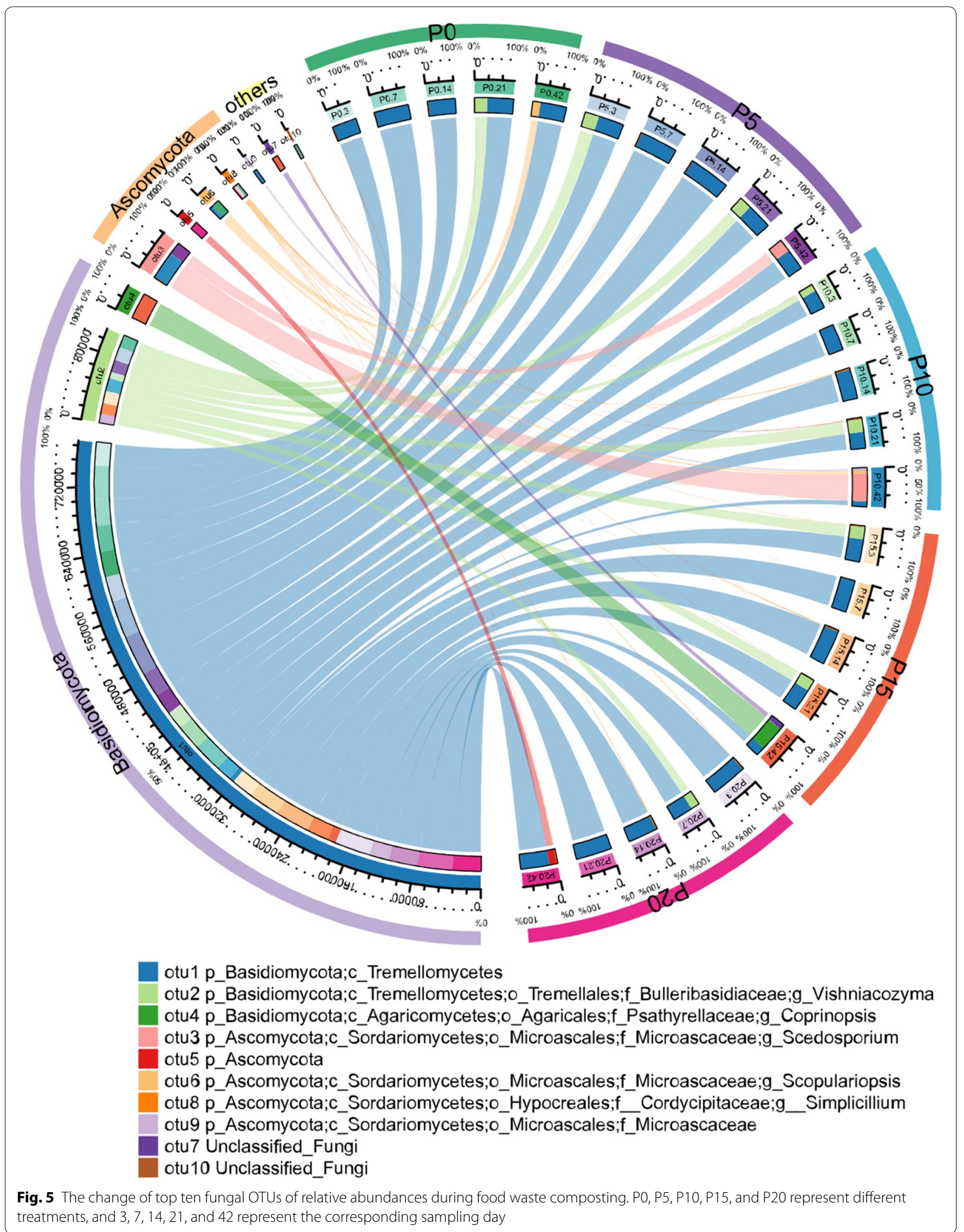


Bray-Curtis dissimilarities in all treatments were from $0.09,0.05,0.02,0.02$, and 0.26 to $0.46,0.41,0.21,0.53$, and 0.87 , respectively, on day $3,7,14,21$, and 42 , which indicated that the fungal OTUs composition in all treatments have the maximum dissimilarity at the end of composting. Therefore, we speculated that adding peat obviously affected fungal OTUs composition in the maturation phase of composting. This result was proved by the change of fungal community composition at phylum and genus levels. That might be because fungal community was influenced by $\mathrm{pH}$ value (Fig. 6b) and $\mathrm{pH}$ value have the most significant different in the maturation phase during composting. Meanwhile, NMDS results suggested that samples tended to cluster together with composting time at the OTU level (Fig. 6a), suggesting a fungal community succession pattern. PERMANOVA also indicated that composting time had a significant effect on OTU diversity and abundance $(p<0.001)$. The result was similar to $\mathrm{Gu}$ et al. [20], where they reported that time influenced fungal variation during chicken manure composting. This was mainly because fungal community was influenced by physicochemical parameters that alter with compost time $[22,54]$. However, PERMANOVA showed that adding peat had no significant influence on fungal community succession throughout composting $(p>0.05)$. That the fungal community was highly dependent on composting time might explain this lack of correlation [55]. A Mantel-test showed a significant correlation between fungal OTU composition and physicochemical parameters $(p<0.001)$.

Canonical correlation analysis (CCA) showed that physicochemical parameters had significant influence on OTU diversity and abundance $(p<0.001)$. CCA1 explained $23.14 \%$ of the variation in OTU composition $(p<0.001)$, and CCA2 explained $17.83 \%$ of the variation $(p<0.05)$. Among all selected physicochemical parameters, $\mathrm{pH}$ value, $\mathrm{MC}$, and $\mathrm{GI}$ had the most significant influence on fungal community succession $(p<0.001)$. Wang et al. [22] reported that $\mathrm{pH}$ value and $\mathrm{MC}$ had significant effects on fungal communities in cow manure composting. Zhao et al. [54] reported that fungal composition was positively correlated with GI and had contribution to composting stability and safety during sludge composting. However, $\mathrm{TN}$ and $\mathrm{NH}_{4}^{+}$had no significant effect on fungal community succession during composting $(p>0.05)$. The result indicated that there might be no direct correlation between fungal community succession and nitrogen conservation during composting. It is well known that fungal populations play a pivotal role in OM degradation and carbon cycle during composting [23]. Zhao et al. [54] also reported that fungal community might affect the function and succession of bacterial strains, but not directly participate in or have less contribution to degrading OM. Therefore, we need to further study the variation of bacterial community of composting in the future.

In conclusion, the present study has confirmed the positive impact of peat on nitrogen conservation during food waste composting. Adding peat elevated the peak temperature of composting, lowered final $\mathrm{pH}$ value, reduced ammonia emissions and increased the final total nitrogen content. Compared to the control, adding 5, 10, 15 , and $20 \%$ peat decreased ammonia emissions by 1.91 , $10.79,23.73$, and $18.26 \%$, respectively, during 42 days of composting. Moreover, adding peat increased fungal community diversity especially during maturation phase. The most two abundant phyla were Basidiomycota and Ascomycota in all treatments throughout the composting process. At the end of composting, in treatments with adding 10 and $15 \%$ peat, the richest fungi were Scedosporium spp. and Coprinopsis spp., respectively. Simultaneously, canonical correlation analyses showed that $\mathrm{pH}$ value, moisture content, and seed germination index had significant association with fungal community
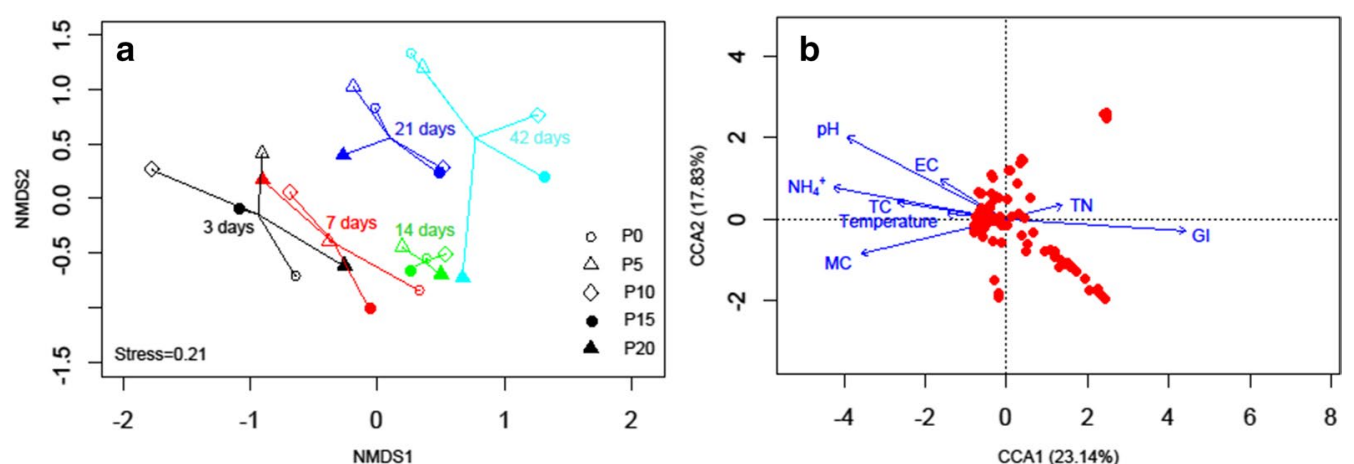

Fig. 6 Nonmetric multidimensional scaling (NMDS) analysis showing fungal community dissimilarity at the total OTU level (a) and canonical correlation analysis (CCA) biplot showing the association between the physicochemical parameters and OTUs (b) during food waste composting 
composition. The study also showed that fungal community and nitrogen conservation had no direct significant relation during composting. Overall, the results suggest that the addition of peat could efficiently enhance nitrogen conservation through reduction of ammonia emissions and $15 \%$ peat addition is the optimal formula for food waste composting.

\section{Acknowledgments}

This work was supported by the National Natural Science Foundation of China [31870598]; the National Key Research and Development Program of the Ministry of Science and Technology of China [2016YFD0600204]; the State Key Program of National Natural Science Foundation of China [31530007]; the Natural Science Foundation of Hunan Province [2020JJ5455]; the Water Conservancy Science and Technology Province in Jiangsu Province [ZQ2018107] and the Open Fund Project of Hunan Engineering Laboratory for Chinese Giant salamander's Resource Protection and Comprehensive Utilization [DNGC2009]. Meanwhile, we would like to thank Dr. Larry Bowman at Yale University for his assistance with English language and grammatical editing.

\section{Authors' contributions}

XT supervised this work. ZH, QL, and XZ performed all the experimental work. ZH wrote this manuscript. QL and XZ edited the whole manuscript. ZH, $\mathrm{KT}$, and XK provided formal analysis of this manuscript. All authors read and approved the final manuscript.

\section{Availability of data and materials}

The datasets used and/or analysed during the current study are available from the corresponding author on reasonable request.

\section{Competing interests}

The authors declare no conflict of interest.

\section{Author details \\ 1 School of Life Sciences, Nanjing University, Nanjing 210023, Jiangsu, China. ${ }^{2}$ College of Agricultural Engineering, Nanyang Normal University, Nan- yang 473061, Henan, China. ${ }^{3}$ Co-Innovation Center for Sustainable Forestry in Southern China, Nanjing Forestry University, Nanjing 210037, Jiangsu, China.}

Received: 27 June 2020 Accepted: 19 October 2020

Published online: 06 November 2020

\section{References}

1. Zhou H, Meng AH, Long YQ, Li QH, Zhang YG (2014) An overview of characteristics of municipal solid waste fuel in China: physical, chemical composition and heating value. Renew Sust Energ Rev 36:107-122

2. Guo WY, Zhou Y, Zhu NW, Hu HG, Shen WH, Huang XX, Zhang TP, Wu PX, Li ZB (2018) On site composting of food waste: a pilot scale case study in China. Resour Conserv Recy 132:130-138

3. Wang XJ, Pan SQ, Zhang ZJ, Lin XY, Zhang YZ, Chen SH (2017) Effects of the feeding ratio of food waste on fed-batch aerobic composting and its microbial community. Bioresour Technol 224:397-404

4. Li ZT, Lu HW, Ren LX, He L (2013) Experimental and modeling approaches for food waste composting: a review. Chemosphere 93(7):1247-1257

5. Chen YT (2016) A cost analysis of food waste composting in Taiwan. Sustainability 8(11):1210

6. Komilis DP, Ham RK (2006) Carbon dioxide and ammonia emissions during composting of mixed paper, yard waste and food waste. Waste Manage 26(1):62-70

7. Wang SG, Zeng Y (2018) Ammonia emission mitigation in food waste composting: a review. BioresourTechnol 248:13-19

8. Wang X, Selvam A, Chan MT, Wong JWC (2013) Nitrogen conservation and acidity control during food wastes composting through struvite formation. Bioresour Technol 147:17-22

9. Al-Jabi LF, Halalsheh MM, Badarneh DM (2008) Conservation of ammonia during food waste composting. Environ Technol 29(10):1067-1073
10. Chan MT, Selvam A, Wong JWC (2016) Reducing nitrogen loss and salinity during 'struvite' food waste composting by zeolite amendment. Bioresour Technol 200:838-844

11. LiY, Luo WH, Li GX, Wang K, Gong XY (2018) Performance of phosphogypsum and calcium magnesium phosphate fertilizer for nitrogen conservation in pig manure composting. Bioresour Technol 250:53-59

12. Kern J, Tammeorg P, Shanskiy M, Sakrabani R, Knicker H, Kammann C, Tuhkanen EM, Smidt G, Prasad M, Tiilikkala K, Sohi S, Gasco G, Steiner C, Glaser B (2017) Synergistic use of peat and charred material in growing media - an option to reduce the pressure on peatlands? J Environ Eng Landsc 25(2):160-174

13. McCrory DF, Hobbs PJ (2001) Additives to reduce ammonia and odor emissions from livestock wastes: a review. J Environ Qual 30(2):345-355

14. Witter E, Kirchmann H (1989) Peat, zeolite and basalt as adsorbents of ammoniacal nitrogen during manure decomposition. Plant Soil 115(1):43-52

15. Robertson RA (1993) Peat, horticulture and environment. Biodivers Conserv 2(5):541-547

16. Klavins M, Purmalis O (2013) Properties and structure of raised bog peat humic acids. J Mol Struct 1050:103-113

17. Farrell $\mathrm{M}$, Jones $\mathrm{DL}$ (2010) Food waste composting: Its use as a peat replacement. Waste Manage 30(8-9):1495-1501

18. Nakasaki K, Hirai H, Mimoto H, Quyen TNM, Koyama M, Takeda K (2019) Succession of microbial community during vigorous organic matter degradation in the primary fermentation stage of food waste composting. Sci Total Environ 671:1237-1244

19. Wang K, Chu C, Li X, Wang W, Ren N (2018) Succession of bacterial community function in cow manure composing. Bioresour Technol 267:63-70

20. Gu WJ, Lu YS, Tan ZY, Xu PZ, Xie KZ, Li X, Sun LL (2017) Fungi diversity from different depths and times in chicken manure waste static aerobic composting. Bioresour Technol 239:447-453

21. Wang X, Selvam A, Lau SSS, Wong JWC (2018) Influence of lime and struvite on microbial community succession and odour emission during food waste composting. Bioresour Technol 247:652-659

22. Wang K, Yin XB, Mao HL, Chu C, Tian Y (2018) Changes in structure and function of fungal community in cow manure composting. Bioresour Technol 255:123-130

23. Tortosa G, Torralbo F, Maza-Marquez P, Aranda E, Calvo C, Gonzalez-Murua C, Bedmar EJ (2020) Assessment of the diversity and abundance of the total and active fungal population and its correlation with humification during two-phase olive mill waste ("alperujo") composting. BioresourTechnol 295:122267

24. Yu H, Huang GH (2009) Effects of sodium acetate as a pH control amendment on the composting of food waste. Bioresour Technol 100(6):2005-2011

25. Yang F, Li GX, Shi H, Wang YM (2015) Effects of phosphogypsum and superphosphate on compost maturity and gaseous emissions during kitchen waste composting. Waste Manage 36:70-76

26. Liu G, Jiang N, Zhang L, Liu Z (1996) Soil physical and chemical analysis and description of soil profiles. China Standard Methods Press 24:266

27. Sanchez-Monedero MA, Roig A, Paredes C, Bernal MP (2001) Nitrogen transformation during organic waste composting by the Rutgers system and its effects on $\mathrm{pH}$, EC and maturity of the composting mixtures. Bioresour Technol 78(3):301-308

28. Dodt M, Roehr J, Ahmed R, Dieterich C (2012) FLEXBAR—flexible barcode and adapter processing for next-generation sequencing platforms. Biology 1(3):895-905

29. Caporaso JG, Kuczynski J, Stombaugh J, Bittinger K, Bushman FD, Costello EK, Fierer N, Pena AG, Goodrich JK, Gordon Jl, Huttley GA, Kelley ST, Knights D, Koenig JE, Ley RE, Lozupone CA, McDonald D, Muegge BD, Pirrung M, Reeder J, Sevinsky JR, Tumbaugh PJ, Walters WA, Widmann J, Yatsunenko T, Zaneveld J, Knight R (2010) QIIME allows analysis of highthroughput community sequencing data. Nat Methods 7(5):335-336

30. Abarenkov K, Henrik NR, Larsson K, Alexander I, Eberhardt U, Erland S, Høiland K, Kjøller R, Larsson E, Pennanen T, Sen R, Taylor A, Tedersoo L, Ursing B, Vrålstad T, Liimatainen K, Peintner U, Köljalg U (2010) The UNITE database for molecular identification of fungi-recent updates and future perspectives. New Phytol 186(2):281-285

31. Wagas M, Nizami AS, Aburiazaiza AS, Barakat MA, Ismail IMI, Rashid MI (2018) Optimization of food waste compost with the use of biochar. $J$ Environ Manage 216:70-81 
32. Liu W, Wang ST, Zhang J, Xu T (2014) Biochar influences the microbial community structure during tomato stalk composting with chicken manure. Bioresour Technol 154:148-154

33. Chen H, Awasthi SK, Liu T, Duan Y, Ren X, Zhang Z, Pandey A, Awasthi MK (2020) Effects of microbial culture and chicken manure biochar on compost maturity and greenhouse gas emissions during chicken manure composting. J Hazard Mater 389:121908

34. Jain MS, Jambhulkar R, Kalamdhad AS (2018) Biochar amendment for batch composting of nitrogen rich organic waste: Effect on degradation kinetics, composting physics and nutritional properties. Bioresour Technol 253:204-213

35. Yang F, Li GX, Yang QY, Luo WH (2013) Effect of bulking agents on maturity and gaseous emissions during kitchen waste composting. Chemosphere 93(7):1393-1399

36. Eklind $Y$, Kirchmann $H$ (2000) Composting and storage of organic household waste with different litter amendments. II: nitrogen turnover and losses. BioresourTechnol 74(2):125-133

37. Awasthi MK, Pandey AK, Bundela PS, Wong JWC, Li RH, Zhang ZQ (2016) Co-composting of gelatin industry sludge combined with organic fraction of municipal solid waste and poultry waste employing zeolite mixed with enriched nitrifying bacterial consortium. Bioresour Technol 213:181-189

38. Wang Q, Awasthi MK, Ren XN, Zhao JC, Li RH, Wang Z, Wang MJ, Chen HY, Zhang ZQ (2018) Combining biochar, zeolite and wood vinegar for composting of pig manure: the effect on greenhouse gas emission and nitrogen conservation. Waste Manage 74:221-230

39. Meng L, Li W, Zhang S, Wu C, Jiang W, Sha C (2016) Effect of different extra carbon sources on nitrogen loss control and the change of bacterial populations in sewage sludge composting. Eco Eng 94:238-243

40. Awasthi MK, Wong JWC, Kumar S, Awasthi SK, Wang Q, Wang MJ, Ren XN, Zhao JC, Chen HY, Zhang ZQ (2018) Biodegradation of food waste using microbial cultures producing thermostable alpha-amylase and cellulase under different $\mathrm{pH}$ and temperature. Bioresour Technol 248:160-170

41. Yang F, Li Y, Han Y, Qian W, Li G, Luo W (2019) Performance of mature compost to control gaseous emissions in kitchen waste composting. Sci Total Environ 657:262-269

42. Awasthi MK, Wang Q, Awasthi SK, Wang M, Chen H, Ren X, Zhao J, Zhang $Z$ (2018) Influence of medical stone amendment on gaseous emissions, microbial biomass and abundance of ammonia oxidizing bacteria genes during biosolids composting. Bioresour Technol 247:970-979

43. Awasthi MK, Wang Q, Chen HY, Wang MJ, Awasthi SK, Ren XN, Cai HZ, Li $\mathrm{RH}$, Zhang ZQ (2018) In-vessel co-composting of biosolid: Focusing on mitigation of greenhouse gases emissions and nutrients conservation. Renew Energ 129:814-823

44. Wong JWC, Fung SO, Selvam A (2009) Coal fly ash and lime addition enhances the rate and efficiency of decomposition of food waste during composting. Bioresour Technol 100(13):3324-3331
45. Wang SP, Zhong XZ, Wang TT, Sun ZY, Tang YQ, Kida K (2017) Aerobic composting of distilled grain waste eluted from a Chinese spiritmaking process: the effects of initial pH adjustment. Bioresour Technol 245:778-785

46. Wang XQ, Cui HY, Shi JH, Zhao XY, Zhao Y, Wei ZM (2015) Relationship between bacterial diversity and environmental parameters during composting of different raw materials. Bioresour Technol 198:395-402

47. Ma C, Hu B, Wei MB, Zhao JH, Zhang HZ (2019) Influence of matured compost inoculation on sewage sludge composting: enzyme activity, bacterial and fungal community succession. Bioresour Technol 294:122165

48. Awasthi MK, Li J, Kumar S, Awasthi SK, Wang Q, Chen HY, Wang MJ, Ren XN, Zhang ZQ (2017) Effects of biochar amendment on bacterial and fungal diversity for co-composting of gelatin industry sludge mixed with organic fraction of municipal solid waste. Bioresour Technol 246:214-223

49. Wakase S, Sasaki H, Itoh K, Otawa K, Kitazume O, Nonaka J, Satoh M, Sasaki T, Nakai Y (2008) Investigation of the microbial community in a microbiological additive used in a manure composting process. Bioresour Technol 99(7):2687-2693

50. Li J, Bao H, Xing W, Yang J, Liu R, Wang X, Lv L, Tong X, Wu F (2020) Succession of fungal dynamics and their influence on physicochemical parameters during pig manure composting employing with pine leaf biochar. Bioresour Technol 297:122377

51. Duan YM, Awasthi SK, Liu T, Chen HY, Zhang ZQ, Wang Q, Ren XN, Tu ZN, Awasthi MK, Taherzadeh MJ (2019) Dynamics of fungal diversity and interactions with environmental elements in response to wheat straw biochar amended poultry manure composting. Bioresour Techno 274:410-417

52. Han ZP, Kautto L, Meyer W, Chen SCA, Nevalainen H (2018) Growth and protease secretion of Scedosporium aurantiacum under conditions of hypoxia. Microbiol Res 216:23-29

53. Nuchdang S, Vatanyoopaisarn S, Phalakornkule C (2015) Effectiveness of fungal treatment by Coprinopsis cinerea and Polyporus tricholoma on degradation and methane yields of lignocellulosic grass. Int Biodeterior Biodegrad 104:38-45

54. Zhao XY, Wei YQ, Zhang F, Tan WB, Fan YY, Xi BD (2019) How do fungal communities and their interaction with bacterial communities influence dissolved organic matter on the stability and safety of sludge compost? Environ Sci Pollut R 26(4):4141-4146

55. Langarica-Fuentes A, Zafar U, Heyworth A, Brown T, Fox G, Robson GD (2014) Fungal succession in an in-vessel composting system characterized using 454 pyrosequencing. FEMS Microbiol Ecol 88(2):296-308

\section{Publisher's Note}

Springer Nature remains neutral with regard to jurisdictional claims in published maps and institutional affiliations. 